\title{
MINAT GENERASI MILENIAL UNTUK BERWIRAUSAHA
}

\author{
M. Iswahyudi ${ }^{1}$ \\ Fakultas Ekonomi \\ Universitas 17 Agustus 1945 Banyuwangi \\ m.iswahyudi@untag-banyuwangi.ac.id
}

\author{
Achmad Iqbal2 \\ Fakultas Ekonomi \\ Universitas 17 Agustus 1945 Banyuwangi \\ iqbalachmad@untag-banyuwangi.ac.id
}

\begin{abstract}
ABSTRAK
Penelitian ini bertujuan untuk menguji pengaruh pendidikan kewirausahaan terhadap minat untuk berwirausaha generasi milenial dengan perceived desirability dan perceived feasibilty sebagai faktor mediasi. Penelitian ini menggunakan metode survey dengan jumlah responden sebanyak 62 responden. Data pada penelitian ini dianalisis menggunakan Partial Least Square (PLS) dengan perangkat lunak warpPLS versi 3.0. Hasil penelitian menunjukkan bahwa pendidikan kewirausahaan tidak mempengaruhi secara langsung minat untuk berwirausaha pada generasi milenial, tetapi minat untuk berwirausaha muncul ketika mendapatkan pendidikan dan mereka mempunyai keinginan (desirability) serta mampu mengelola (feasibility) kemampuan tersebut untuk berwirausaha.
\end{abstract}

Kata Kunci : Minat Berwirausaha; Generasi Milenial; Pendidikan Kewirausahaan; Desirability; Feasibility

ABSTRACT
This research aims to examine the effect of entrepreneurship education on the interest in millennial generation entrepreneurship with perceived desirability and perceived feasibility as a mediating factor. This research uses a survey method with a total of 62 respondents. The data in this study were analyzed using Partial Least Square (PLS) with warpPLS version 3.0 software. The results showed that entrepreneurship education does not directly affect the interest in entrepreneurship in millennial generations, but their interest in entrepreneurship arises when they get education and they have desirability and are able to manage this ability for entrepreneurship.

Keywords: Entrepreneurship Intentions; Millenial Generation; Entrepreneurial Education; Perceived Desirability; Perceived Feasibility

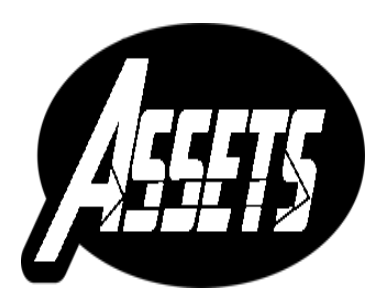

ASSETS

Jurnal Akuntansi dan Pendidikan

Vol. 7 No. 2

Hlmn. 95-104

Madiun, Oktober 2018 p-ISSN: 2302-6251 e-ISSN: 2477-4995

Artikel masuk: 15 Oktober 2018 Tanggal diterima: 30 Oktober 2018 


\section{PENDAHULUAN}

Wirausaha dianggap sebagai jawaban untuk mengatasi permasalahan ekonomi, terutama untuk mendorong pertumbuhan ekonomi serta perkembangan teknologi (Dissanayake, 2013; Sondari, 2014). Agar pertumbuhan ekonomi dapat dicapai sesuai dengan yang ditargetkan diperlukan usaha terencana dan terstruktur. Salah satu upaya yang dapat dilakukan untuk mendorong terciptanya lebih banyak wirausahawan adalah dengan memberikan pendidikan kewirausahaan.

Selain berdampak pada peningkatkan pertumbuhan ekonomi, kegiatan wirausaha juga terkait dengan menciptakan lapangan pekerjaan (Sondari, 2014). Beberapa negara berkembang dikawasan Asia Tenggara Malaysia, Srilanka dan Indonesia meyakini bahwa untuk mengurangi jumlah peningkatan pengangguran yang signifikan selama lima tahun terakhir, Wirausaha dianggap sebagai solusi untuk masalah pengangguran yang terus berkembang terutama pada negara-negara tersebut (Thriwakala, 2011). Jadi dapat dikatakan bahwa wirausaha menjadi solusi atas persoalan ekonomi suatu negara. Karena wirausaha menjadi solusi, perlu dilakukan suatu cara untuk menciptakan wirausaha baru.

Pendidikan kewirausahaan meliputi pengembangan pada berbegai bidang seperti pengetahuan, kapasitas, perilaku dan kualitas individu dalam menumbuhkan sikap kewirausahaan (Liñán, 2014). Jadi dapat disimpulkan bahwa fokus pendidikan kewirausahaan berada pada proses untuk menciptakan suatu usaha tertentu yang pada akhirnya akan memunculkan dan menumbuhkan minat untuk berwirausaha.

Dalam beberapa tahun terakhir, penelitian mengenai kewirausahaan mengalami peningkatan baik dari segi kuantitas maupun kualitasnya (Turker, 2008; Walter \& Dohse, 2009; Lorz, 2011). Hal ini muncul karena minat wirausaha berpengaruh terhadap pertumbuhan ekonomi, perkembangan teknologi, dinamisasi proses inovatif serta penciptaan lapangan pekerjaan (Appelbaum, Roy, \& Gilliland, 2011; Bonet, Peris-Ortiz, \& Pechua'n, 2011; Cambra f, Florin, Perez, \& Whitelock, 2011).

Minat untuk berwirausaha menjadi penting untuk diteliti karena setiap upaya atau perilaku pasti diawali dari adanya minat untuk melakukan perilaku tersebut (Huang, Chou, \& Lee, 2010; Lee \& Ngoc, 2010; Lindblom \& Tikkanen, 2010; Zhang \& Duan, 2010). Dengan demikian, diasumsikan bahwa kita dapat mengelola hal-hal yang mempengaruhi minat untuk berwirausaha dengan cara yang positif agar memunculkan minat positif terhadap perilaku berwirausaha, sehingga pertumbuhan ekonomi, perkembangan teknologi dan penyediaan lapangan pekerjaan yang memadai dapat tercapai.

Pendidikan kewirausahaan sebagai pemicu munculnya minat berwirausaha akan lebih efektif apabila didorong oleh keinginan seseorang untuk melakukan sesuatu (desirability) serta pengelolaan sesuatu untuk mencapai suatu tujuan (feasibility). Hal ini berarti, ketika seseorang mempunyai desirability dan feasibility yang tinggi akan memicu munculnya minat untuk berwirausaha yang tinggi pula. Hal ini dikarenakan dua faktor ini merupakan faktor motivasional seseorang untuk melakukan sesuatu. Minat seseorang 
untuk melakukan sesuatu ditentukan dari kemampuan untuk menangkap adanya faktor motivasional (Ajzen, 1991).

Beberapa penelitian telah membuktikan mengenai pengaruh desirability dan feasibility. Guzmán-Alfonso \& Guzmán-Cuevas (2012) melakukan penelitian di Amerika latin untuk membuktikan apakah kedua faktor tersebut mampu untuk menciptakan minat peningkatan penciptaan usaha. Hasil penelitiannya menunjukkan bahwa kedua faktor tersebut menjadi faktor penentu minat kewirausahaan. Hattab (2014) meneliti mengenai minat kewirausahaan pada mahasiswa di British University. Hasil penelitian menunjukkan bahwa terdapat hubungan yang positif antara pendidikan kewirausahaan, desirability, feasibility dan minat kewirausahaan.

Salah satu teori yang banyak mendapat perhatian dari para peneliti adalah Theory of Planned Behavior (TPB) yang dikemukakan oleh Ajzen (1991). Teori ini menjelaskan bahwa minat atau keinginan diawali oleh adanya kontrol perilaku, norma subjektif dan sikap terhadap perilaku. dalam hal ini TPB dianggap mampu untuk memprediksi dan menjelaskan perilaku seseorang dengan berfokus pada minat individu untuk melakukan tindakan atau perilaku tertentu. TPB banyak diaplikasikan sebagai teori yang mendasari berbagai model untuk menjelaskan minat berwirausaha. Mengacu pada TPB, Krueger, Reilly, \& Carsrud (2000) mencoba mengembangkan teori ini untuk menjelaskan beberapa variabel yang mendahului terjadinya minat berwirausaha. Berawal dari adanya perceived desirability dan perceived feasibility dari suatu ide untuk menciptakan suatu usaha.

Penelitian ini dilakukan untuk menguji pengaruh positif pendidikan kewirausahaan terhadap minat berwirausaha, pengaruh positif pendidikan kewirausahaan terhadap minat berwirausaha melalui perceived desirability, pengaruh positif pendidikan kewirausahaan terhadap minat berwirausaha melalui perceived feasibility. Penelitian ini dilakukan pada generasi muda "milenial" yang lahir pada tahun 90-an sampai awal tahun 2000 karena mereka yang merasakan dampak dari sulitnya dalam hal mencari pekerjaan. Untuk itu mahasiswa fakultas ekonomi Universitas 17 Agustus 1945 Banyuwangi dipilih sebagai objek penelitian karena selain sebagai generasi muda, mereka juga telah mendapatkan pendidikan kewirausahaan.

\section{METODE PENELITIAN}

Penelitian ini menggunakan pendekatan kuantitatif dengan mengacu pada paradigma positivis. Penelitian ini dilakukan pada mahasiswa Universitas 17 Agustus 1945 (Untag) Banyuwangi. Untag dipilih sebagai objek penelitian karena Universitas ini merupakan Universitas tertua di Banyuwangi yang lulusannya telah banyak menjadi wirausahawan. Penelitian dikhususkan pada mahasiswa semester akhir program studi akuntansi. Program studi akuntansi dipilih karena identik dengan kewirausahaan.

Teknik pengambilan sampel dalam penelitian ini menggunakan teknik convenience sampling. Convenience sampling dijadikan sebagai teknik pemilihan sampel karena jumlah populasi (mahasiswa akuntansi yang lahir pada akhir tahun 80-an sampai dengan awal tahun 2000) tidak diketahui. Namun 
(Sholihin. \& Ratmono., 2013:12) menyatakan bahwa sampel minimum yang menjadi syarat adalah sebanyak sepuluh kali jumlah jalur. Pada penelitian ini terdapat lima jalur, sehingga sampel minimum yang harus digunakan sebanyak 50 responden.

Data yang digunakan dalam penelitian ini bersumber dari data primer yang diambil dengan metode survey melalui penyebaran kuesioner. Kuesioner dalam penelitian ini diambil dari penelitian yang dilakukan Efrata (2016) sehingga memungkinkan validitas dan reliabilitasnya terjamin. Penyebaran kuesioner dilakukan menggunakan google form sehingga penyebaran kuesioner dapat lebih cepat dan efektif.

Uji hipotesis dilakukan dengan mengevaluasi nilai path coefficient dan nilai p. Penelitian ini menggunakan tingkat signifikansi 5\%. Semua hipotesis pada penelitian ini mempunyai arah hubungan (one tailed), sedangkan output warpPLS 3.0 adalah untuk pengujian two tailed. Sehingga, nilai p yang tampil pada output PLS akan dibagi dua untuk pengujian one tailed. Jadi hipotesis diterima jika besarnya koefisien jalur sesuai dengan arah hubungan yang dihipotesiskan dan besarnya nilai p yang telah dibagi dua kurang dari 0,05 .

\section{HASIL PENELITIAN DAN PEMBAHASAN}

Pengumpulan data dimulai pada awal bulan Agustus sampai dengan awal bulan september 2018. Sebanyak 80 kuesioner telah disebar, terdapat 12 kuesioner tidak kembali serta 6 kuesioner tidak dapat digunakan, sehingga terdapat 62 kuesioner yang dapat diolah.

Langkah pertama uji menggunakan warpPLS adalah melakukan uji Outer Model. Pada tahap uji outer model dilakukan dengan tiga tahapan, pertama melakukan pengujian validitas konvergen, kedua pengujian validitas diskriminan serta pengujian reliabilitas. Kemudian pada langkah selanjutnya dilakukan uji inner model menggunakan dua parameter pengukuran yaitu $\mathrm{R}^{2}$ dan path coefficient. Hasil uji hipotesis ada pada Lampiran 1.

Hasil analisis menunjukkan bahwa tidak terdapat pengaruh antara pendidikan kewirausahaan terhadap minat generasi milenial untuk berwirausaha, jadi hipotesis pertama ditolak. Hal ini menunjukkan pendidikan kewirausahaan pada generasi milenial yang dilakukan pada perguruan tinggi belum mampu menumbuhkan minat mereka untuk berwirausaha. Hasil penelitian ini menunjukkan hasil yang sejalan dengan penelitian sebelumnya yang dilakukan (Lanero et al., 2011) pada mahasiswa yang telah lulus sarjana di Spanyol. Hasil penelitian menunjukkan bahwa pendidikan kewirausahaan masih belum mampu untuk menumbuhkan minat mahasiswa untuk berwirausaha.

Temuan hasil penelitian ini juga mendukung hasil penelitian yang dilakukan oleh (Lorz, 2011), dimana hasil penelitian menunjukkan ketidakmampuan pendidikan atau program kewirausahaan dalam hal meningkatkan minat untuk berwirausaha. Hasil penelitian sebelumnya, menunjukkan beberapa alasan mengapa pendidikan kewirausahaan belum mampu untuk memunculkan minat berwirausaha. Salah satunya dikarenakan pendidikan kewirausahaan masih bersifat awareness education. 
Hal ini dapat diartikan bahwa pendidikan kewirausahaan belum dapat menjawab permasalahan pengangguran di Indonesia. Bharanti, Idrus, Zain, \& Solimun (2012) menyatakan bahwa terdapat beberapa faktor yang menyebabkan meningkatnya pengangguran pada lulusan tinggi di Indonesia. Pertama, karena tidak sesuainya kompetensi dari lulusan dengan apa yang dibutuhkan dunia kerja. Kedua, karena adanya keinginan pencari kerja untuk mencari pekerjaan yang aman dan tidak beresiko. Ketiga karena banyaknya pencari kerja dan kurangnya serapan tenaga kerja. Dari alasan kedua dan ketiga perlu untuk dilakukan adanya suatu tindakan untuk merubah pola pikir dari mencari pekerjaan menjadi menyediakan lapangan pekerjaan. Hal ini akan berhasil dilakukan jika minat untuk menjadi berwirausahanya positif. Ketika minat untuk berwirausaha positif, maka perilaku berwirausaha akan dapat diwujudkan yang pada akhirnya akan menyerap banyak tenaga kerja.

Hipotesis kedua pada penelitian ini merupakan hipotesis pengaruh mediasi yang menyatakan bahwa perceived desirability memediasi hubungan antara pendidikan kewirausahaan dan minat untuk berwirausaha generasi milenial. Hasil analisis menunjukkan bahwa hipotesis kedua diterima (lampiran 2). Hasil penelitian ini sejalan dengan penelitian (Liñán, 2014)

Hasil penelitian ini menunjukkan bahwa adanya pendiidkan kewirausahaan terbukti meningkatkan minat, keinginan dan pilihan mahasiswa untuk berwirausaha. namun tanpa adanya keinginan atau ketertarikan yang sebelumnya dimiliki oleh individu untuk menjadi wirausaha akan sulit untuk mendorong minat mereka menjadi wirausaha jika hanya mengandalkan pendidikan kewirausahaan semata.

Hipotesis ketiga pada penelitian ini merupakan hipotesis pengaruh mediasi yang menyatakan bahwa perceived feasibility memediasi hubungan antara pendidikan kewirausahaan dan minat untuk berwirausaha generasi milenial. Hasil analisis menunjukkan bahwa perceived feasibility memediasi hubungan antara pendidikan kewirausahaan dan minat untuk berwirausaha, jadi hipotesis kedua diterima (lampiran 3). Hasil penelitian ini sejalan dengan penelitian yang dilakukan Guerrero, Rialp, \& Urbano, (2008). Hasil penelitiannya menunjukkan bahwa perceived feasibility terbukti mampu memperkuat hubungan antara pendidikan kewirausahaan dan minat berwirausaha.

Hasil ini menunjukkan bahwa aspek atau dorongan dari dalam maupun luar individu memberikan pengaruh terhadap kecenderungan generasi milenial untuk berwirausaha. Kemampuan individu dalam mengelola keinginan mampu meningkatkan minat mereka untuk berwirausaha. Dengan kata lain pendidikan kewirausahaan yang diberikan akan mampu meningkatkan minat generasi milenial untuk berwirausaha, namun tanpa adanya kemampuan dalam mengelola keinginannya untuk berwirausaha akan sangat sulit mendorong minat mereka menjadi wirausaha jika hanya mengandalkan pendidikan kewirausahaan semata. 


\section{SIMPULAN}

Hasil penelitian menunjukkan bahwa minat untuk berwirausaha pada generasi milenial tidak muncul ketika mereka mendapat pendidikan kewirausahaan, tetapi minatnya untuk berwirausaha muncul ketika setelah mereka mendapat pendidikan kewirausahaan mereka mempunyai keinginan untuk melakukan atau menerapkan apa yang didapatnya pada saat mendapat pendidikan kewirausahaan. Selain itu, minat mereka untuk berwirausaha muncul ketika setelah mereka mendapat pendidikan kewirausahaan mereka juga berusaha untuk mengelola apa yang didapatnya selama pendidikan untuk mencapai tujuan mereka. Untuk itu jika ingin memunculkan niat berwirausaha pada generasi milenial, mereka tidak cukup hanya diberikan pendidikan atau pelatihan mengenai kewirausahaan tetapi juga diberikan mengenai bagaimana para generasi milenial mempunyai keinginan menjadi seorang wirausaha (desirability) serta kemampuan dalam melakukan sesuatu dengan baik (feasibility).

Penelitian ini memiliki keterbatasan pada tingginya kuesioner yang tidak kembali dan tidak dapat digunaka, yaitu sebesar 22,5\%. Saran peneliti untuk penelitian selanjutnya perlu diberikan hadiah tertentu kepada responden agar minatnya dalam mengisi kuesioner lebih besar sehingga tingkat kuesioner yang tidak kembali dapat diminimalkan. Selain itu, untuk penelitian selanjutnya mengenai pengaruh pendidikan kewirausahaan terhadap minat untuk menjadi wirausaha perlu memperhatikan mengenai intensitas pendidikan kewirausahaan yang dilakukan sehingga memungkinkan didapat hasil yang lebih baik.

\section{DAFTAR PUSTAKA}

Ajzen, I. (1991). The theory of planned behavior. Orgnizational Behavior and Human Decision Processes, 50, 179-211.

Ajzen, I., \& Fishbein, M. (1980). Understanding Attitudes and Predicting Social Behavior. New Jersey: Prentice Hall International Inc. Budiadji.

Appelbaum, S.H., Roy, M. and Gilliland, T. (2011). Globalization of performance appraisals: theory and applications. Management Decision, 49(4), 570-585.

Bharanti, B. El., Idrus, M., Zain, D., \& Solimun. (2012). Pengaruh Pendidikan Kewirausahaan dan Stereotip Gender terhadap Intensi Kewirausahaan yang Dimediasi oleh Kebutuhan Berprestasi dan Efikasi Diri. JUrnal Aplikasi Manajemen, 10(3).

Bonet, F.J.P., Peris-Ortiz, M. and Pechua'n, I. (2011). Basis for a general theory of organizations. Management Decision, 49(2), 270-283.

Cambra f, J., Florin, J., Perez, L., \& Whitelock, J. (2011). Inter-firm market orientation as antecedent of knowledge transfer, innovation and value creation in networks. Management Decision, 49(3), 444-467.

Dissanayake, D. (2013). The Impact of Perceived Desirability and Perceived Feasibility on Entrepreneurial Intention among Undergraduate Students in Sri Lanka: An Extended Model. The Kelaniya Journal of Management, 2(1), 113. 
Efrata, T. C. (2016). Pendidikan kewirausahaan terhadap minat berwirausaha: mediasi perceived desirability, mediasi perceived feasibility dan moderasi model peran. Disertasi. Program Doktor Ilmu Manajemen Universitas Brawijaya.

Guerrero, M., Rialp, J., \& Urbano, D. (2008). The impact of desirability and feasibility on entrepreneurial intentions : A structural equation model, 3550 .

Guzma, C. (2012). Entrepreneurial intention models as applied to Latin America, 25(5), 721-735.

Guzmán-Alfonso, C., Guzmán-Cuevas, J. (2012). Entrepreneurial intention models as applied to Latin America. Journal of Organiz Ational Change Management, 25, 721-735.

Hattab, H. W. (2014). Impact of Entrepreneurship Education on Entrepreneurial Intentions of University Students in Egypt. The Journal of Entrepreneurship, 23(1), $1-18$.

Huang, J.Y., Chou, T.C. and Lee, G. G. (2010). Imitative innovation strategies: understanding resource management of competent followers. Management Decision, 48(6), 952-975.

Krueger, N. F., Reilly, M. D., \& Carsrud, A. L. (2000). Competing Models Of Entrepreneurial Intentions, 9026(98), 411-432.

Krueger, N.F., Brazeal, D. V. (1994). Entrepreneurial potential and potential entrepreneurs. Entrepreneurship Theory and Practice, 18, 91-91.

Lanero, A., Vázquez, J. L., \& Gutiérrez, P. (2011). The impact of entrepreneurship education in European universities : an intention-based approach analyzed in the Spanish area, 111-130.

Lee, S. H., \& Ngoc, H. T. B. (2010). Investigating the on-line shopping intentions of Vietnamese students: An extension of the theory of planned behaviour. World Transactions on Engineering and Technology Education, 8(4), 471-476.

Liñán, F. (2014). Intention-Based Models of Entrepreneurship Education, (January 2004).

Lindblom, A. and Tikkanen, H. (2010). Knowledge creation and business format franchising. Management Decision, 48(2), 179-188.

Lorz, M. (2011). The Impact of Entrepreneurship Education on Entrepreneurial Intention, (3966).

Ramı́rez, A. ., Orejuela, A. ., \& Vargas, G. . (2010). New perspectives for the managerial entrepreneurship. International Entrepreneurship and Management Journal, 6(2), 203 - 219.

Sholihin., \& Ratmono. (2013). Analisis SEM-PLS dengan WarpPLS 3.0. Yogyakarta: Andi.

Sondari, M. C. (2014). Is Entrepreneurship Education Really Needed?: Examining the Antecedent of Entrepreneurial Career Intention. Procedia Social and Behavioral Sciences, 115(Iicies 2013), 44-53.

Thriwakala, S. (2011). The Determinants of Entrepreneurial Intention among Academics in Srilanka. In International Conferenceon Economics and Finance Research IPEDR.

Turker, D. (2008). Which factors affect entrepreneurial intention of university students? Journal of European Industrial Training, 33(2), 142-159. 
Walter, S.G., Dohse, D. (2009). The interplay between entrepreneurship education and regional knowledge potential in forming entrepreneurial intentions.

Zhang, J. and Duan, Y. (2010). The impact of different types of market orientation on product innovation performance: evidence from Chinese manufacturers. Management Decision, 48(6), 849-867.

\section{LAMPIRAN}

Lampiran 1. Gambar model hasil penelitian

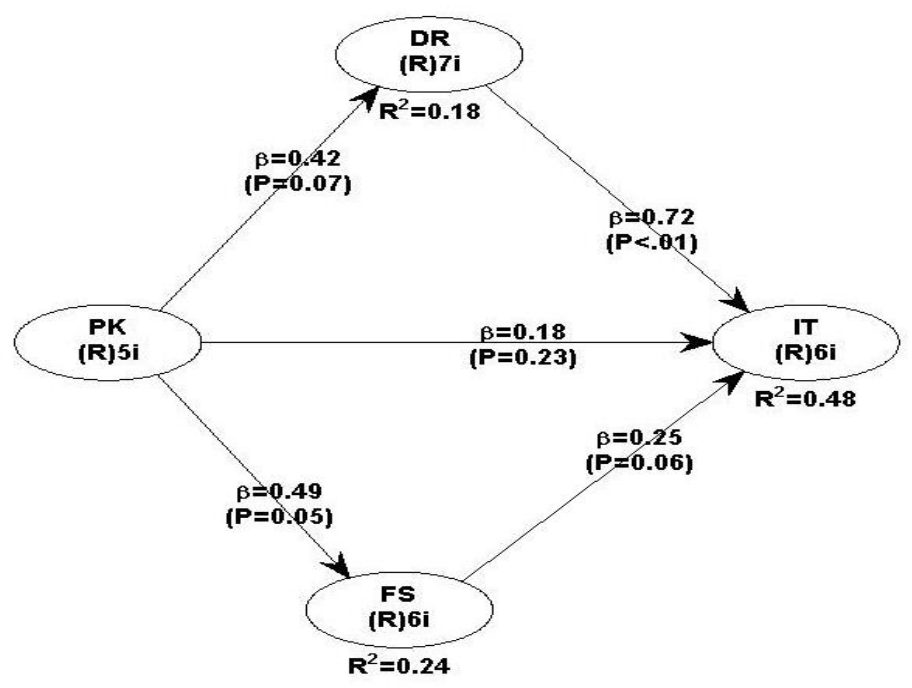

Lampiran 2. Hasil uji mediasi perceived desirability terhadap hubungan pendidikan kewirausahaan dan minat untuk berwirausaha

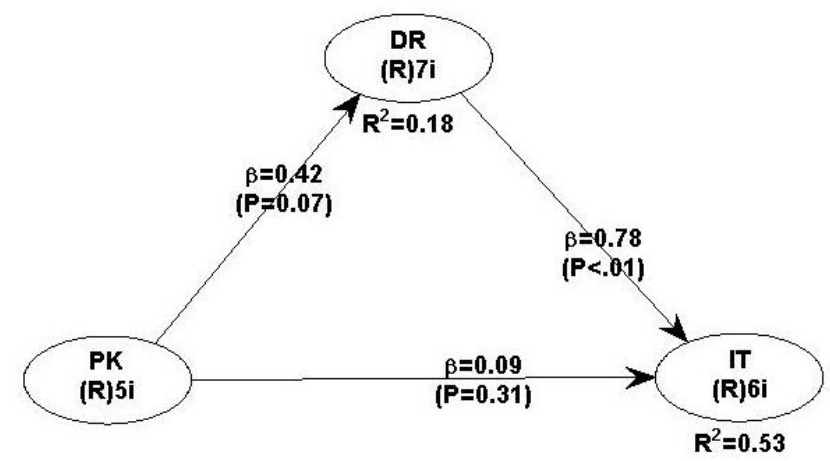

Path coefficients
\begin{tabular}{|c|c|c|c|}
\hline & PK & IT & DR \\
\hline PK & & & \\
IT & 0.092 & & 0.785 \\
\cline { 1 - 1 } DR & 0.421 & & \\
\cline { 1 - 1 } &
\end{tabular}

P values
\begin{tabular}{|c|c|c|c|}
\hline & PK & IT & DR \\
\hline PK & & & \\
IT & 0.306 & & $<0.001$ \\
\hline DR & 0.068 & & \\
\cline { 1 - 1 } & & &
\end{tabular}


Lampiran 3. Hasil uji mediasi perceived feasibility terhadap hubungan pendidikan kewirausahaan dan minat untuk berwirausaha

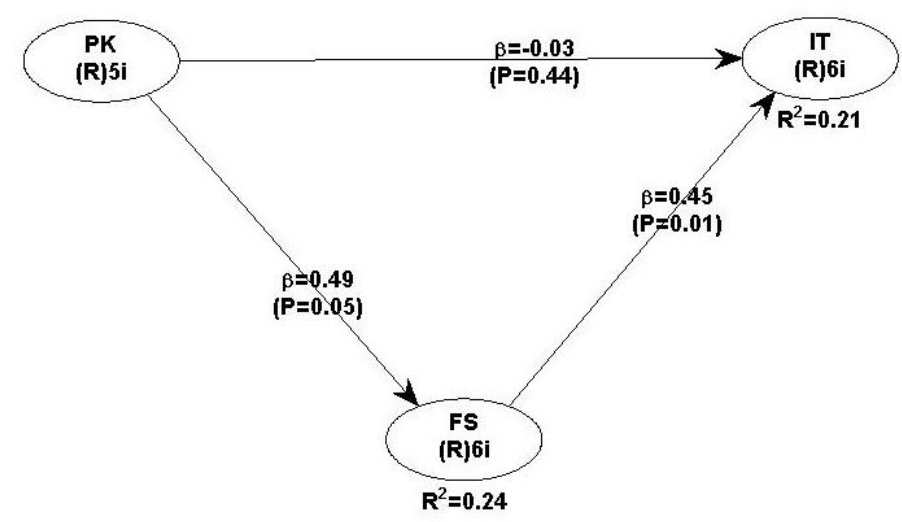

Path coefficients
\begin{tabular}{|c|c|c|c|}
\hline & PK & IT & FS \\
\hline PK & & & \\
\hline IT & -0.034 & 0.449 \\
\hline FS & 0.490 & & \\
\hline
\end{tabular}

P values
\begin{tabular}{|c|c|c|c|}
\hline & PK & IT & FS \\
\hline PK & & & \\
\hline IT & 0.444 & & 0.012 \\
\hline FS & 0.050 & & \\
\hline
\end{tabular}


Lampiran 4. Instrumen Penelitian

Pendidikan Kewirausahaan

- Pendidikan wirausaha telah meningkatkan pemahaman saya mengenai karakter yang harus dimiliki oleh seorang pengusaha

- Pendidikan kewirausahaan telah meningkatkan pemahaman saya mengenai langkah-langkah yang harus dilakukan untuk memulai usaha.

- Pendidikan kewirausahaan telah meningkatkan pemahaman saya tentang manajemen praktis untuk memulai usaha

- Pendidikan kewirausahaan meningkatkan kemampuan saya untuk membangun jejaring bisnis

- Pendidikan kewirausahaan telah meningkatkan kemampuan saya untuk mengidentifikasi peluang usaha.

Perceived Desirability

- Berwirausaha berarti memberikan lebih banyak manfaat untuk saya

- Mendirikan usaha merupakan hal yang menarik bagi saya

- Jika saya memiliki kesempatan beserta sumber daya yang dibutuhkan, saya ingin memulai usaha

- Mendirikan usaha akan memberi kepuasan bagi saya

- Dari beberapa pilihan pekerjaan yang ada, saya memilih untuk berwirausaha

- Keluarga akan mendukung keputusan saya untuk berwirausaha

- Teman teman dekat yang berada dilingkungan kampus akan mendukung keputusan saya untuk berwirausaha

Perceived Feasibility

- Memulai usaha, merupakan hal yang mudah bagi saya

- Saya cukup siap untuk memulai usaha

- Saya dapat menjalankan proses bisnis yang dibutuhkan untuk memulai usaha

- Saya memahami beberapa ketrampilan praktis yang dibutuhkan untuk memulai usaha

- Saya memahami bagaimana suatu proyek kewirausahaan dijalankan

- Jika saya mendirikan suatu usaha, saya yakin akan sukses

Minat Untuk Berwirausaha

- Saya siap untuk melakukan apa saja agar menjadi pengusaha

- Tujuan profesi saya adalah menjadi pengusaha

- Saya akan berupaya untuk memulai menjadi pengusaha

- Saya berkomitmen untuk menjadi pengusaha pada masa mendatang

- Saya memiliki keingingan yang serius untuk menjadi pengusaha

- Saya memiliki tekad yang kuat untuk menjadi pengusaha pada masa yang akan datang. 